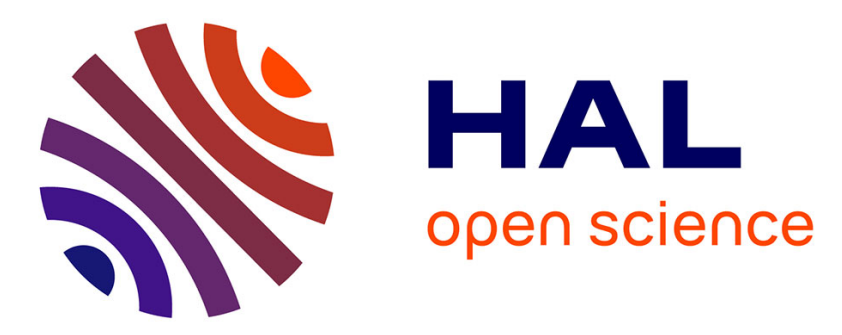

\title{
Assessment of HCLL-TBM optimum welding sequence scenario to minimize welding distortions
}

\author{
O. Doyen, N. Rizzo, L. Forest, J. Tosi, N. Thomas, M. Zmitko
}

\section{To cite this version:}

O. Doyen, N. Rizzo, L. Forest, J. Tosi, N. Thomas, et al.. Assessment of HCLL-TBM optimum welding sequence scenario to minimize welding distortions. SOFT 2016 - 29th edition of the Symposium on Fusion Technology, Sep 2016, Prague, Czech Republic. cea-02442290

\section{HAL Id: cea-02442290 https://hal-cea.archives-ouvertes.fr/cea-02442290}

Submitted on 16 Jan 2020

HAL is a multi-disciplinary open access archive for the deposit and dissemination of scientific research documents, whether they are published or not. The documents may come from teaching and research institutions in France or abroad, or from public or private research centers.
L'archive ouverte pluridisciplinaire HAL, est destinée au dépôt et à la diffusion de documents scientifiques de niveau recherche, publiés ou non, émanant des établissements d'enseignement et de recherche français ou étrangers, des laboratoires publics ou privés. 


\title{
Assessment of HCLL-TBM optimum welding sequence scenario to minimize welding distortions
}

\author{
Olivier DOYEN ${ }^{\mathrm{a}}$, Nicola RIZZO ${ }^{\mathrm{a}}$, Laurent FOREST ${ }^{\mathrm{a}}$, Jérôme TOSI ${ }^{\mathrm{a}}$, Noel THOMAS ${ }^{\mathrm{b}}$, Milan \\ ZMITKO $^{\mathrm{c}}$
}

\author{
${ }^{a} C E A, D E N$, DM2S, SEMT, Laboratoire des Technologies d'Assemblage, F-91191 Gif-sur-Yvette, France. \\ ${ }^{b}$ ATMOSTAT, F-94815 Villejuif, France. \\ ${ }^{c}$ Fusion for Energy (F4E), Josep Pla 2, Barcelona, Spain.
}

\begin{abstract}
The ITER HCLL-TBM (Helium Cooled Lithium Lead Test Blanket Module) box assembly development implies the welding development of the following components: the Box and the Stiffening Grid (SG) made of vertical and horizontal Stiffening Plates (noted respectively v-SP and h-SP). This multi-chamber box structure in EUROFER97 steel is made of plates cooled by multiple meandering channels where circulates pressurized helium. For the assembly of these components, characterized by numerous multipass welds, Gas Tungsten Arc Welding (GTAW) is envisaged as reference process. Moreover, the TBM has large dimensions and thin plates which makes it very sensitive to welding distortions and is problematic regarding the assembly feasibility and compliance with geometric tolerances. This paper presents the numerical simulation and experimental work performed to optimize the $\mathrm{v}$-SP to box assembly sequence, which is the most critical assembly regarding distortions, in order to minimize welding distortions.

One of the technical lock of this study is high calculation times needed for this large component which implies to set up a simplified welding simulation method. The study is composed of three main phases: an experimentalnumerical study of a T-joint fillet mock-up GTAW used to develop the preliminary welding procedure and to validate a simplified simulation method, a numerical optimization of the v-SP to box welding sequence via the simplified method, and the experimental application of the optimized v-SP to Box welding sequence on the TBM mock-up. The calculation and comparison of four different v-SP to box welding sequences allowed to identify the best sequence regarding welding distortions and to apply it experimentally.
\end{abstract}

Keywords: ITER, HCLL-TBM, welding sequence, simulation, experimental validation, distortions.

\section{Introduction}

The ITER HCLL-TBM (Helium Cooled Lithium Lead Test Blanket Module) box assembly development implies the welding development of the following components (fig. 1.a): the Box, made of the First Wall (FW) and Side Cap (SC), and the Stiffening Grid (SG), made of the vertical and horizontal Stiffening Plates (noted respectively v-SP and h-SP). This multi-chamber box structure is made of plates cooled by multiple meandering channels where circulates pressurized helium. For the assembly of these components, characterized by numerous welds, automatic multipass Gas Tungsten Arc Welding (GTAW) is envisaged as reference process [1].

Moreover, the TBM has large dimensions (fig.1a) and thin plates (thickness of $11 \mathrm{~mm}$ for $\mathrm{v}-\mathrm{SP}$ and $30 \mathrm{~mm}$ for the Box) which makes it very sensitive to welding distortions and is problematic regarding the assembly feasibility and compliance with geometric tolerances. The goal of this study is to optimize the TBM welding sequence so as to minimize welding distortions. The choice made is first to weld the v-SP inside of the Box and then to insert and assemble the h-SPs. We focus on the most critical assembly regarding distortions which is $\mathrm{v}-\mathrm{SP}$ to Box assembly (fig. 1.b). Indeed, the main difficulty is to be able to insert all h-SPs into the Box after v-SP welding; once all h-SPs are inserted and clamped, no major distortion should occur during h-SP welding. TBM distortion optimization is evoked in the literature [2-4] and is treated only at a local scale on elementary and small components. Nevertheless, in ITER framework, distortion studies at the global component scale were carried out on a vacuum vessel sector [5-7].

The methodology used and presented in this paper implies experimental and numerical simulation work on a TBM mock-up made of P91 steel (X10CrMoVNb9-1) instead of EUROFER 97 for the real TBM, their weldability behavior is very similar. This mock-up has the same dimensions as the real TBM (fig. 1.a) but channels are present only in the v-SP and are generated by drilling. The approach is first to set up the welding parameters and operatory conditions, then to identify the best welding sequence by simulation and at last to reproduce it experimentally and check the consistency with the calculation. One of the technical challenges of the numerical study is the very high calculation times needed for this large component which implies to set up a simplified welding simulation method. Several simplified methods exist to decrease calculation times of large component welding [8-16].

Specifically, three main phases follow one another in this study: an experimental-numerical study of a T-joint fillet mock-up GTAW (representative of the TBM welds and illustrated in fig. 1.c) used to develop the preliminary welding procedure and to validate the 
simplified welding simulation method, a numerical optimization of the v-SP to Box welding sequence via the simplified method validated in the first phase, and the experimental application of the optimized $\mathrm{v}$-SP to Box welding sequence on the TBM mock-up. We first present the experimental work performed on T-joint and
TBM mock-ups, then we detail the numerical simulation of the relevant mock-ups, and at last and evoke the obtained results which allowed us to identify the best welding sequence, among the tested four, and to apply it experimentally.

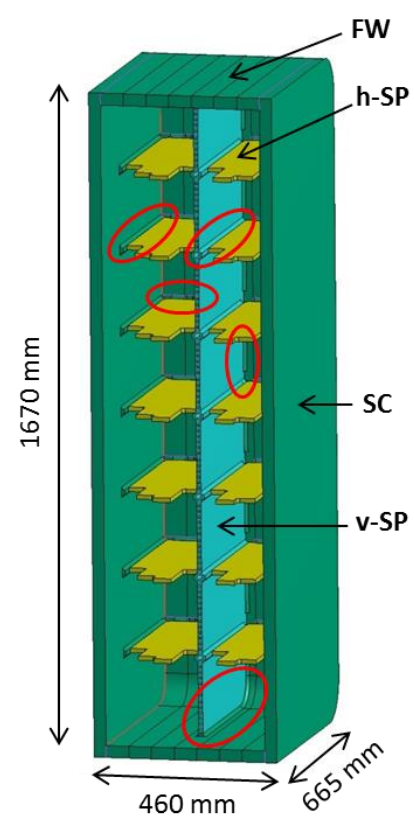

(a)

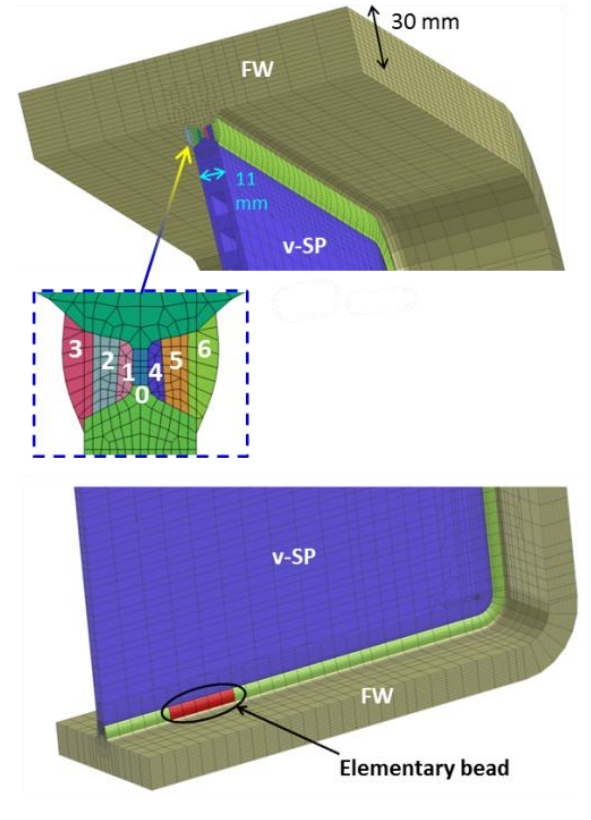

(b)
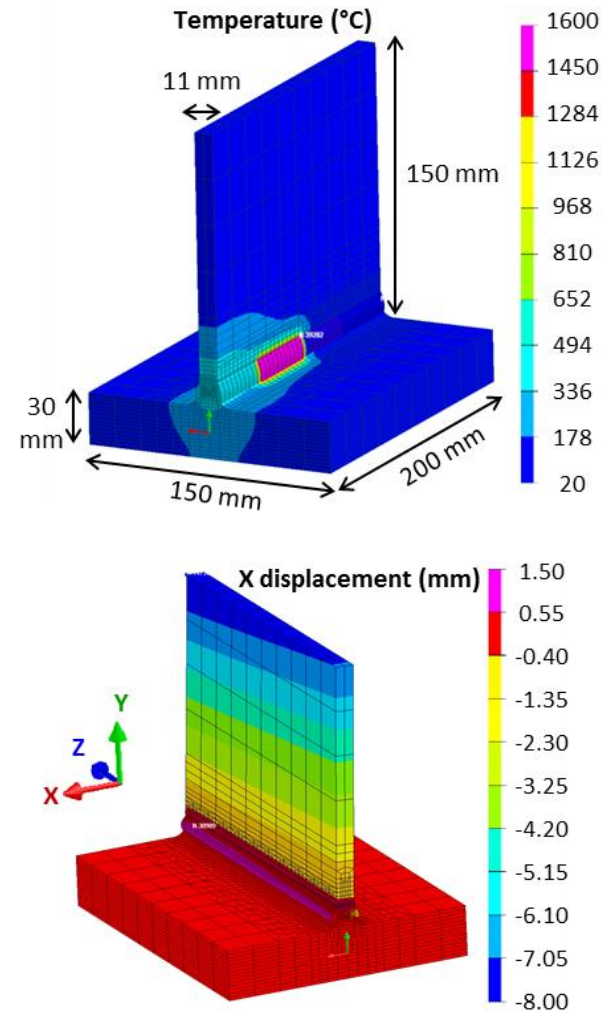

(c)

Fig. 1. Schematic of the TBM mock-up and welds localization (a); Mesh images for v-SP to Box welding simulation (b); Temperature during welding (up) and X displacements after welding (down) for the T-joint mock-up (c).

\section{Experimental work}

\subsection{T-joint mock-up welding}

The T-joint mock-up is representative of most of the TBM welds (fig. 1.c). In particular, it has the same chamfer geometry and it is composed of two plates with the same thicknesses as V-SP and Box (respectively 11 and $30 \mathrm{~mm}$ ). No channels are present. This mock-up is used to develop the preliminary welding procedure, applied on the TBM mock-up, and to validate welding simulation via welding instrumentation and post welding measurements.

The X shaped welding groove is machined on the $11 \mathrm{~mm}$ thick plate (fig. 1.b). The welding filler metal used is Thermanit MTS3 (wire diameter of $1.2 \mathrm{~mm}$ ). After a tack weld, 7 welding passes are performed: one root pass to guarantee the full penetration and six filling passes (three passes in each groove side). The welding sequence used implies to fill completely one groove side before filling the second one. Automatic GTAW welding is performed with the following main parameters: flat position with a $10^{\circ}$ torch angle versus the vertical direction, $2 \%$ thoriated tungsten electrode with a tip angle of $60^{\circ}$ and whose tip is placed at 3 to $4 \mathrm{~mm}$ from the chamfer top, Argon shielding gas, $9 \mathrm{~cm} / \mathrm{min}$ welding speed, a direct current between $120 \mathrm{~A}$ and $250 \mathrm{~A}$ with a voltage of 10 to $11 \mathrm{~V}$, and a wire speed of $1300 \mathrm{~mm} / \mathrm{min}$ for the filling passes. A set of ceramic weld backings is disposed in the groove (on the not welded side) to prevent the weld pool to fall off during the first filling passes. It is covered by an aluminum tape inside of which the inert shielding gas circulates. Two appendixes are added at the beginning and end of the mock-up to allow the power source increase and decrease. Clamping is minimal to get the greatest distortions in order to be compared more easily to the simulation: the $11 \mathrm{~mm}$ plate only lays on a support.

Several macrographs are performed on the welded mock-ups to identify the molten zones and heat affected zones (HAZ). Temperature evolutions during welding are measured via several thermocouples located around the welding groove at different depth. Maximum temperatures from $400{ }^{\circ} \mathrm{C}$ up to $1400{ }^{\circ} \mathrm{C}$ are measured for each welding pass. The macrograph and temperature measurements allow to calibrate the heat input model used in the simulation. Welding distortions are measured to validate the T-joint mock-up welding simulation. Displacements of the $11 \mathrm{~mm}$ thick plate edge are measured during welding via two displacement sensors. Moreover, distortions of half welded and fully welded 
mock-ups are also characterized via dimensional probing on four points located along each edge of the two plates.

\section{$2.2 \mathrm{v}-\mathrm{SP}$ to Box welding}

The v-SP to Box welding (fig. 2.) was developed and performed on a dedicated facility made of a robot, allowing the welding head movement along 6 axes, a manipulator, allowing to displace the TBM and its clamping tools along 3 axis (2 translations and 1 rotation) and a GTAW electric power supply. A specific welding torch was developed. It is has a $2 \mathrm{~m}$ long arm with narrow dimensions (9 $\mathrm{cm}$ high and $5 \mathrm{~cm}$ wide) which allow the access to the welding grooves inside of the TBM. The TBM mock-up clamping is ensured by refractory metal frame and struts.
In order to adapt to the specific welding equipment and Box environment, the welding procedure specification, preliminarily set up for the $\mathrm{T}$-joint mock-up, has been modified by adjusting the kind of current (pulsed current instead of direct current for arc stability improvement) and its value, the feeding wire speed and the voltage. The welding sequence was chosen after obtaining the simulation results. The best welding sequence (called sequence 1 in the following and in fig. 5.) was used. A post welding heat treatment (PWHT) is performed on the clamped TBM after the whole welds are performed (PWHT not simulated) for distortions and metallurgical reasons. Then, after unclamping, a dimensional probing is carried out to assess the welding distortions.
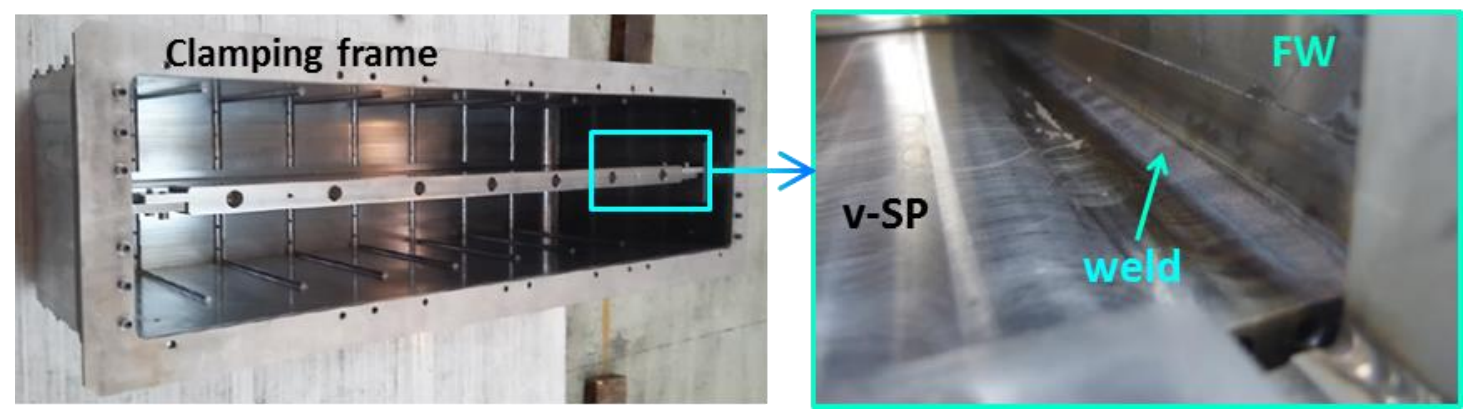

Fig. 2. Picture of a welded TBM mock-up.

\section{Numerical simulation work}

\subsection{T-joint mock-up welding}

\subsubsection{Complete simulation}

We developed a complete transient simulation, using SYSWELD, whose objective is to set up and validate the simplified simulation (paragraph 3.1.2). This simulation implies a thermal-metallurgical calculation followed by a mechanical calculation. The mesh, displayed in fig. 1.c, is composed of linear elements. The same P91 thermomechanical properties are used for base and filler metal. They are dependent on the temperature and taken from experimental characterizations up to 800 or 1000 ${ }^{\circ} \mathrm{C}$ and are extrapolated up to $1450{ }^{\circ} \mathrm{C}$ (melting temperature).

For the thermal-metallurgical analysis, phase transformations are taken into account. A Leblond model [17] is calibrated to assess phase proportions during the base and filler metal transformation to austenite and a Koistinen Marburger model [18] is used for austenite to martensite transformation. Heat input is represented via a Goldak heat source model [19] calibrated for each pass with regards to the shapes and sizes of the molten zones and HAZ identified on the weld macrographs and to the temperature evolutions measured during welding. A heat transfer coefficient of 20 W.m-2.K-1 is applied on the external mock-up surface to model convection. A $20{ }^{\circ} \mathrm{C}$ initial temperature is imposed at the beginning of welding.

For the mechanical analysis, we used an elastoplastic law with an isotropic hardening model and a Von Mises plasticity criterion. A cut-off temperature, above which the cumulative plastic strain is set to zero, is taken equal to the melting temperature. Specific material properties are applied to the non-welded pass and filler metal: until it reaches the cut-off temperature, a fictive material with very weak mechanical resistance and no thermal dilatations is taken into account in order not to interact mechanically with the pieces during heating. Different mechanical properties and thermal dilatations values are taken for base and filler metal (considered ferritic), martensite and austenite. The phase transformation effects on mechanical results are taken into account via a phase mixture law and a transformation induced plasticity calculation. As clamping conditions, we blocked the displacements of the nodes belonging to one of the $30 \mathrm{~mm}$ thick plate edges.

Calculation is performed with large stains and displacements. We verified indeed by simulation that using the small displacements hypothesis had a significant effect on welding distortions (up to $20 \%$ ). We also noticed that, in our case, phase transformations could not be neglected with regards to distortions: a difference of up to $10 \%$ exists between calculations made with and without phase transformations.

\subsubsection{Simplified simulation}

Several simplified methods exist to assess welding stresses and/or strains on large components with reasonable calculation times such as: shell elements [8], local remeshing [9], local/global method [10-11] and inherent strains [12-14]. We chose to use the block dumping method [15-16] which is adapted to strain calculations. It is not the fastest method, in comparison with the inherent strain method for example, but it allows to adopt a physical approach and ensures a satisfying accuracy. 
This method consists in applying uniformly a specific thermal cycle to elementary beads deposited successively. An elementary bead can be made of an entire welding pass or a portion of it. The thermal cycle, representative of welding, is adjusted for each pass. For a given pass, the relevant thermal cycle is chosen as the average of the nodal thermal cycles of the same pass in the complete transient simulation described previously. The average is calculated on the nodes of the mock-up middle section so as to avoid edge effects. A correction coefficient may be used to obtain the precise fusion zone size. Apart from the heat input, all the other numerical and material data, mesh, boundary and initial conditions are identical to the one described in the complete simulation.

The elementary bead length is adjusted to obtain a good agreement between the complete and simplified simulation on distortions. The smaller the bead length, the better the agreement and the longer the calculation times. We found that an elementary bead length equal to the quarter of the whole pass length is enough to get a satisfying consistency with the complete simulation (a difference on displacements of less than $5 \%$ is obtained). An elementary bead of the last filling pass is illustrated in fig. 1.c. Those beads are deposited according to the welding speed of the relevant pass. Between the simplified and complete simulation, the calculation time gain obtained is equal to 5.5 .

\section{2 v-SP to Box welding}

The v-SP to Box welding simulation was developed using SYSWELD and Visual Environment (for pre and post processing). The block dumping method adjusted for the T-joint mock-up is applied; 266 elementary beads are used (fig. 1.b). The mesh consists of an extrusion of the T-joint mock-up mesh on the whole TBM length, with some adaptations in the corners and some fillings to obtain the final v-SP dimension (fig. 1.b). The whole Box is not meshed: indeed, as explained later in paragraphs 4.1.1 and 4.1.2, simulation shows that the 30 $\mathrm{mm}$ thick plate does not distort unlike the $11 \mathrm{~mm}$ thick plate. We verified that a $300 \mathrm{~mm}$ wide plate mesh with appropriate clamping conditions (node displacements blocking of the lateral faces) is enough to model the Box. The other simulation data (models, material data, numerical parameters, boundary and initial conditions) are identical to the one described for the T-joint mock-up simulation. The v-SP clamping is made by blocking the node displacements at the struts and screws location, in accordance with the experimental clamping. After welding, unclamping is simulated by releasing all the displacement blocking conditions apart from a few nodes of the FW.

Four different welding sequences are calculated and compared as regards to distortions (fig. 3.). In sequence 2 , the whole pass length is welded at once and the pass order alternates from one groove side to another. In sequences 1, 3 and 4, each pass is welded starting at the middle of total length (i.e. from the inside to the outside of the Box). The pass order alternates from one groove side to another for sequence 4 unlike sequence 3 where one groove side is filled completely before filling the second one. For sequence 1, only half of the pass is welded at once (except for pass 1) from the outside to the inside of the Box, and the pass order alternates from one groove side to another (except for passes $4 b / 5 b$, $2 a / 3 a, 5 a / 6 a$ and $2 b / 3 b$ ) and at the same time from the bottom to the top of the v-SP (fig. 3). Sequence 1 is more complicated than the others: it was built in accordance with experimental accessibility constraints and after the calculation results of sequences 2 to 4 which are more general and theoretical choices.

\begin{tabular}{|c|c|c|c|c|c|c|c|c|}
\hline & \multicolumn{2}{|c|}{ Sequence 1} & \multicolumn{2}{|c|}{ Sequence 2} & \multicolumn{2}{|c|}{ Sequence 3} & \multicolumn{2}{|c|}{ Sequence 4} \\
\hline$\#$ & Pass & Traj. & Pass & Traj. & Pass & Traj. & Pass & Traj. \\
\hline 1 & 0 & $\mathrm{~b}$ then $\mathrm{a}$ & 0 & $\mathrm{c}$ & 0 & $a$ then $b$ & 0 & $a$ then $b$ \\
\hline 2 & 4 & $\mathrm{a}$ & 1 & $\mathrm{~d}$ & 1 & $a$ then $b$ & 1 & $a$ then $b$ \\
\hline 3 & 1 & $\mathrm{~b}$ then $\mathrm{a}$ & 4 & $\mathrm{c}$ & 2 & $a$ then $b$ & 4 & $a$ then $b$ \\
\hline 4 & 4 & $\mathrm{~b}$ & 2 & d & 3 & $a$ then $b$ & 2 & $a$ then $b$ \\
\hline 5 & 5 & $\mathrm{~b}$ & 5 & $\mathrm{c}$ & 4 & $a$ then $b$ & 5 & $a$ then $b$ \\
\hline 6 & 2 & $\mathrm{a}$ & 3 & d & 5 & $a$ then $b$ & 3 & $a$ then $b$ \\
\hline 7 & 3 & $\mathrm{a}$ & 6 & $\mathrm{c}$ & 6 & $a$ then $b$ & 6 & $a$ then $b$ \\
\hline 8 & 6 & $\mathrm{~b}$ & & & & & & \\
\hline 9 & 5 & a & & & & 114 & & \\
\hline 10 & 6 & $\mathrm{a}$ & & & 3 & 0 & & \\
\hline 11 & 2 & $\mathrm{~b}$ & & & & & & \\
\hline 12 & 3 & $\mathrm{~b}$ & & & & & & \\
\hline
\end{tabular}

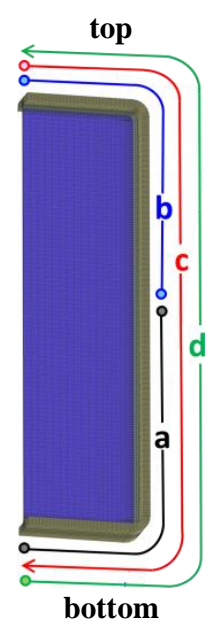

Fig. 3. Representation of the four calculated v-SP to Box welding sequences.

\section{Results and discussion}

\subsection{T-joint mock-up welding}

\subsubsection{Comparison experiment versus simulation}

On the T-joint mock-up welding distortions, experiment and simulation are in good qualitative agreement. Displacements are compared in $\mathrm{X}$ and $\mathrm{Y}$ directions (respectively perpendicular to the thin plate and perpendicular to the thick plate). We notice in both cases that only the thin plate is distorted and that the displacements distribution is rather uniform along the weld length for a given distance from the weld (fig. 1.c). Close to the welds, displacements are weak and their value increase with the distance to the weld to reach a 
maximum on the thin plate edge. On the half welded and fully welded mock-ups the thin plate bends on the same side between simulation and experiment. During welding, we observe the same tendencies regarding the thin plate edge displacement between measurement and simulation: during heating the plate bends towards one side because of thermal dilatation of the beads and during the cooling phase it bends towards the other side because of shrinkage.

From a quantitative point of view, simulation overestimates distortions during and after welding. In particular, calculated displacements are $25 \%$ higher than the one measured on the $\mathrm{X}$ directions after welding. This agreement experiment versus simulation could be improved by modifying the heat input model parameters. Since we adopt a comparative approach to compare different welding sequences we chose to keep the distortions overestimated so as to facilitate the sequences comparison. The good T-joint mock-up welding simulation consistency allows us to analyze the v-SP to Box welding simulation results with a comparative approach.

\subsubsection{Welding recommendations}

By simulation, we compared distortions created by two different welding sequences with identical passes orientations: for the first one, a groove side is filled completely before filling the other one, and for the second one, the pass order alternates from one groove side to another. The distortions induced by the first sequence are significantly higher than for the second one (maximal final plate edge displacement of $8 \mathrm{~mm}$ for the first one versus $2 \mathrm{~mm}$ for the second one). Moreover, we compared four different welding sequences which present the same pass order but different passes orientations. Although the pass orientation effect on distortions is found to be weaker than the pass order effect, this effect is significant (differences up to $13 \%$ are noticed). Nevertheless, no clear recommendation can be made regarding passes orientations: the differences can change sign during welding (negative differences at half welding can become positive at the end of welding). It is thus advised to use a welding sequence which alternates the pass order from one groove side to another to produce smaller welding distortions. The transposition of this conclusion to $\mathrm{V}$-SP to Box welding may be possible although the clamping conditions are very different and may affect the distortion behavior.

\section{2 v-SP to Box welding}

\subsubsection{Welding distortions results}

In the following, we focus mostly on displacements in $\mathrm{X}$ direction (perpendicular to $\mathrm{v}$-SP), because it is the most problematic direction versus $\mathrm{h}-\mathrm{SPs}$ insertion and because it presents the highest displacement values.

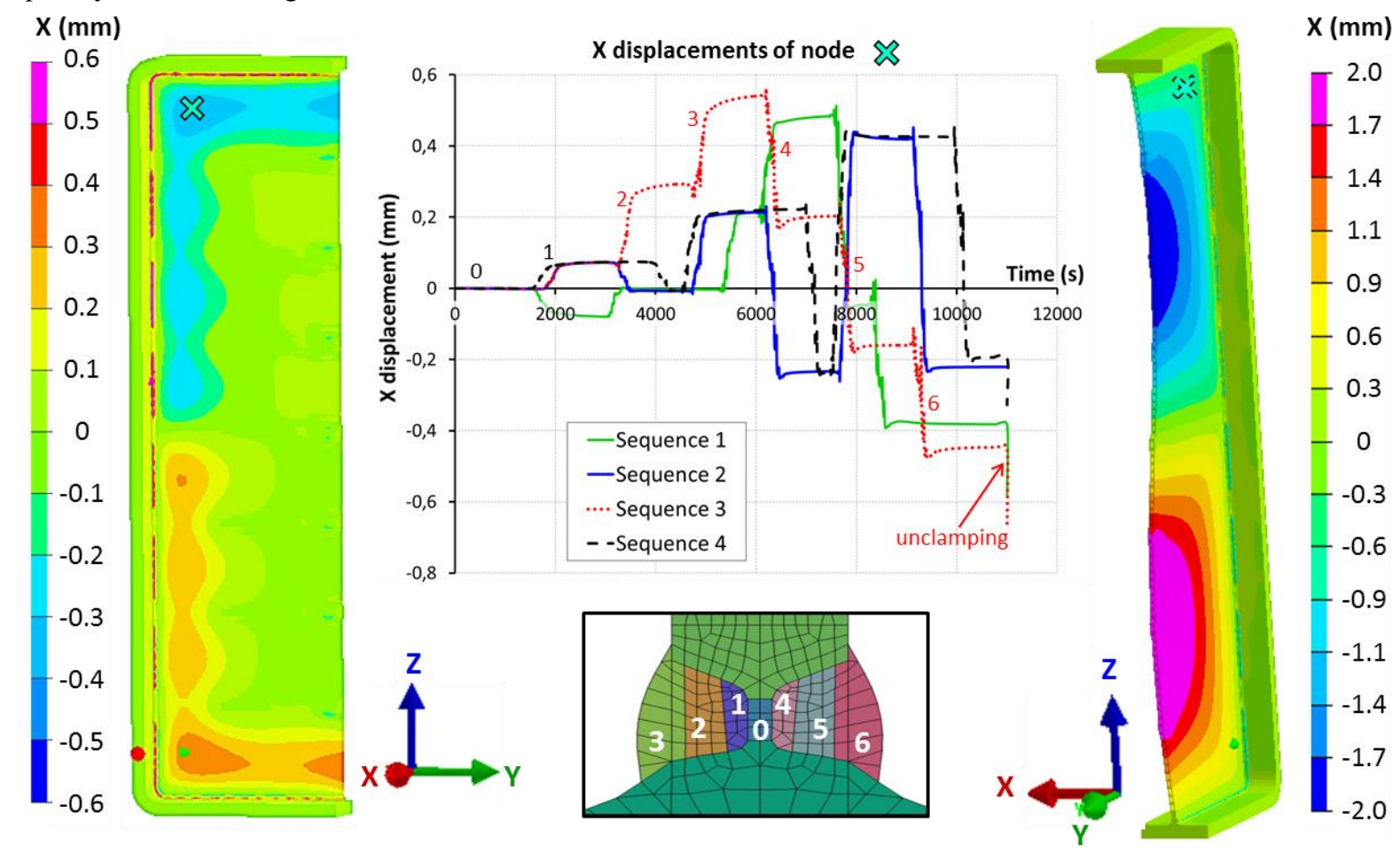

Fig. 4. Calculated X displacements for v-SP to Box welding: after sequence 1 and before unclamping (left), during welding for the four sequences and for the node enlightened by a cross (top), and after unclamping for sequence 1 with deformations amplified 10 times (right).

After welding and before or after unclamping, the distortions distribution in the pieces is similar for the last three sequences, only their values differ. For sequence 1, whose results are presented in fig. 4, the welding distortion distribution is similar to the last three sequences apart from the sign of the v-SP bottom half displacements which are positive instead of being negative. For a given time during welding, distortion distribution differs from one sequence to another depending on the pass location being welded. 
During welding and before unclamping, distortions are weak for the four sequences due to clamping. The maximum displacements are found in $\mathrm{X}$ direction (with maximum values of about $0.6 \mathrm{~mm}$ ) and are located in the $\mathrm{V}-\mathrm{SP}$ between its center (where the struts are placed) and the welds (fig. 4.). The evolution with time of $\mathrm{X}$ displacements in the most distorted zone is presented in fig. 4: the effect of heating and cooling phase of each pass can be observed for the four sequences.

After welding and unclamping, large $\mathrm{X}$ displacements are produced for the four sequences in the $\mathrm{v}$-SP, unlike the FW. Globally, for sequences 2 to 4 , the $\mathrm{v}-\mathrm{SP}$ presents a curved profile with maximum displacements at the center of the remaining edge up to 6 $\mathrm{mm}$ for the sequence producing the largest distortions (fig. 5.). For sequence 1, the V-SP shows a S-curved profile (fig. 4 and 5) which can be explained by the passes order that alternates from both groove side and vSP top/bottom (unlike the other sequences for which a given pass is welded completely, by two halves or entirely, before starting a new pass). For the four sequences, $\mathrm{Y}$ displacements up to $-1.5 \mathrm{~mm}$ are concentrated in a zone from the v-SP edge, around the

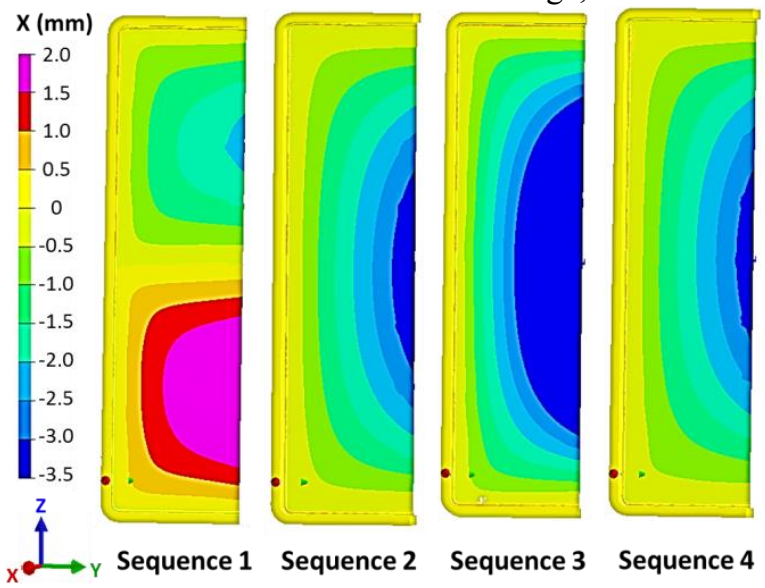

screw locations, to the center of it (fig. 5.). Those displacements have negative values: the V-SP width is thus slightly smaller after welding and unclamping than before welding.

\subsubsection{Qualitative comparison experiment versus simulation}

No quantitative comparison was performed between simulation and experiment (i.e. for sequence 1) because a PWHT was made on the TBM mock-up before unclamping and measuring welding distortions (PWHT not simulated). Indeed, as explained in the following, among others for distortions and metallurgical reasons, PWHT is strongly recommended. However, since we noticed for the TBM sub-components that PWHT tends to reduce the welding distortion values without modifying their main distribution [1], a few qualitative elements can be compared and are in accordance. As simulated, almost no distortion is measured in the FW, unlike in the v-SP. The v-SP S-curved profile is verified experimentally and the maximal $\mathrm{X}$ displacement measured is $1.3 \mathrm{~mm}$ (compared to $2.6 \mathrm{~mm}$ for sequence 1 simulation without PWHT).

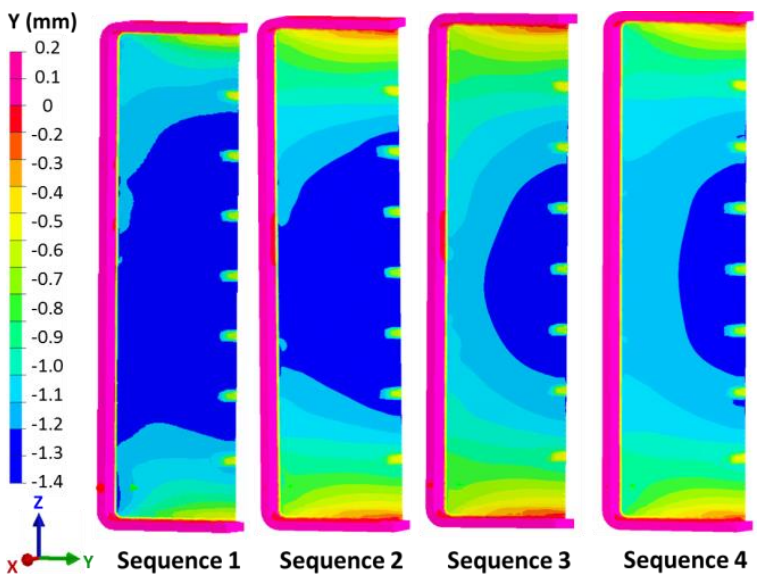

Fig. 5. Calculated X (left) and Y (right) displacements for the four v-SP to Box welding sequences after unclamping.

\subsubsection{TBM mock-up welding recommendations}

As evoked before, sequence 3 generates the largest distortions. The main difference with the other sequences comes from the fact that the pass order does not alternate from one groove side to another. This alternation seems to be one of the key points as regards to welding distortions: final $\mathrm{X}$ displacements values are close for sequences 2 and 4 (fig. 5.). These two sequences also have the smallest displacement gradients in the v-SP (from 0 to $-3.6 \mathrm{~mm}$ for sequence 2 and from 0 to -3.4 $\mathrm{mm}$ for sequence 4). Nevertheless, in our case, the relevant value to consider is the absolute local displacements. Although creating higher displacement gradients (from -2.2 to $2.6 \mathrm{~mm}$ ), sequence 1 produces the smallest absolute local displacements (due to the Scurved profile): after unclamping, the maximum $\mathrm{X}$ and $Y$ displacements are respectively $2.6 \mathrm{~mm}$ and $1.5 \mathrm{~mm}$ as regards with $-3.6 \mathrm{~mm}$ and $-1.5 \mathrm{~mm}$ for sequence $2,-6$ $\mathrm{mm}$ and $-1.5 \mathrm{~mm}$ for sequence 3 and $-3.4 \mathrm{~mm}$ and -1.4 $\mathrm{mm}$ for sequence 4 . As a result, sequence 1 is the best sequence for our issue. This sequence could probably be improved by alternating the order of passes $4 b / 5 b, 2 a / 3 a$, $5 \mathrm{a} / 6 \mathrm{a}$ and $2 \mathrm{~b} / 3 \mathrm{~b}$. Moreover, by comparing sequence 2 and 4 , we notice that welding half a pass or the whole pass at once does not seem to create large differences.

For all sequences, final $\mathrm{X}$ displacements after unclamping are important. We evaluate that the maximum acceptable $\mathrm{X}$ displacement to correctly insert the h-SPs after unclamping is about $+/-2 \mathrm{~mm}$. X displacements are small before unclamping (as calculated), but the clamping tools dimensions do not allow to insert the h-SPs before unclamping. Consequently, simulation shows that at least one PWHT is necessary to reduce distortions: one after welding and maybe another one at the middle of the welding sequence. The measurements performed on the TBM mock-up after PWHT and unclamping show that with the best welding sequence (sequence 1) the maximum displacement is inferior to the limit of acceptability. This means that a PWHT at half of the $\mathrm{v}$-SP welding sequence is not compulsory with the best sequence. 


\section{Conclusion}

Welding parameters and operatory conditions were preliminary adjusted on a T-joint mock-up. The relevant welding simulation was developed to setup and validate a simplified simulation method which allows to significantly decrease calculation times. Simulation results are in good agreement with the experiment on distortions during and after welding. The simplified method and simulation data were used to simulate the vSP to Box welding, which is the most critical assembly versus distortions. Four different welding sequences were calculated and compared. In all cases, only the vSP distorts unlike the Box and the main distortions occur perpendicularly to the $\mathrm{v}$-SP. Before unclamping, distortions are limited unlike after unclamping. In all cases, a PWHT is found to be necessary before unclamping to obtain acceptable distortions. One of the key points to minimize welding distortions is to alternate the weld pass order from one groove side to another. The best welding sequence regarding distortions is identified. This sequence was applied experimentally on a facility developed specifically for the TBM mock-up welding. Measured distortions are qualitatively in accordance with the simulation.

\section{Acknowledgments}

This work was performed by CEA within the framework of a specific contract concerning the development for ITER of manufacturing procedures for the industrial ATMOSTAT (ALCEN group) and Fusion For Energy (F4E).

\section{References}

[1] M. Zmitko, N. Thomas, A. LiPuma, L. Forest, L. Cogneau, J. Rey, H. Neuberger, Y. Poitevin, The European ITER Test Blanket Modules: Progress in development of fabrication technologies towards standardization, Fusion Engineering and Design 96-97 (2015).

[2] T. Kuroda, K. Furuya et al., Welding and Cutting Characteristics of Blanket/First Wall Module to Back Plate for Fusion Experimental Reactor, Fusion Engineering 1 (1995) 341-344.

[3] T. Jayakumar, E. R. Kumar, Indian Test Blanket Module in ITER - Development of RAFM Steel and Fabrication Technology, Advances in Science and Technology 94 (2014) 1-11.

[4] H. Serizawa, D. Mori, H. Murakawa, Basic numerical study on gap influence of residual stress and distortion during High-Brightness Laser Butt Welding, Transactions of JWRI 42 (2) (2013).

[5] L. Jones et al., ITER vacuum vessel sector manufacturing development in Europe, Fusion Eng. Des. 75-79 (2005) 607-612.

[6] L. Jones et al., Manufacturing preparations for the European Vacuum Vessel Sector for ITER, Fusion Eng. Des. 87 (2012) 700-705.

[7] J. Guirao et al., A study of the influence of electron beam welding sequences on the ITER vacuum vessel prototype VATS, Fusion Eng. Des. 86 (2011) 2805-2811.

[8] L.E. Lindgren, Modelling for residual stresses and deformations due to welding - 'Knowing what is not necessary to know', Mathematical Modelling of Weld Phenomena 6 (2002) 491-518.

[9] L.E. Lindgren et al., Automatic remeshing for threedimensional finite element simulation of welding, Comp. Meth. Appl. Mech. Engrg. 147 (1997) 401-409.

[10] [B. Souloumiac, F. Boitout, J.M. Bergheau, A new localglobal approach for the modelling of welded with steel component distortions, Mathematical modelling of weld phenomena 6 (2002) 573-590.

[11] Y.G. Duan, Y. Vincent, F. Boitout, J.-B. Leblond and J.-M. Bergheau, Prediction of welding residual distortions of large structures using a local/global approach, Journal of Mechanical Science and Technology 21 (10) (2007) 17001706.

[12] D Deng et al., Numerical simulation of welding distortion in large structures, Comput. Methods Appl. Mech. Engrg. 196 (2007) 4613-4627.

[13] Y. Ueda, M. G Yuan, Prediction of residual stresses in butt welded plates using inherent strains, J. Engrg. Mater. Technol. 115 (10) (1993) 417-423.

[14] M. Yuan, Y. Ueda, Prediction of residual stresses in welded T- and I-Joints using inherent strains, J. Engrg. Mater. Technol. 118 (4) (1996) 229-234.

[15] P. Mrvar et al., Welding Sequence Definition Using Numerical Calculation, Welding journal 90 (8) (2011) 148S-151S.

[16] E. Feulvarch, V. Robin and J. Bergheau, Thermometallurgical and mechanical modelling of welding - application to multipass dissimilar metal girth welds, Science and Technology of Welding and Joining 16 (13) (2011) 221-226.

[17] JB. Leblond, J. Devaux, A new kinetic model for anisothermal metallurgical transformations in steels including effect of austenite grain size, Acta Materialia 32 (1984) 137-146.

[18] DP. Koistinen, RE. Marburger, A general equation prescribing the extent of the austenite martensite transformations in pure iron-carbon alloys and plain carbon steels, Acta Materialia 7 (1) (1959) 59-60.

[19] J. Goldak et al., A new finite element model for welding heat sources, Metallurgical Transactions B 15 (2) (1984) 299-305. 